5. Дэвис Дж.С. Статистический анализ данных в геологии: В 2 кн.Кн. 1. - М.: Недра, 1990. -319с.

6. Колесников В.П. Основы интерпретации электрических зондирований. - М.: Науч. мир, 2007. -247 с.

7. Петров А.В. Теоретические основы обработки геофизических данных: Учеб. пособие. - М., 2004. - 37c.

8. Петров А.В., Юдин Д.Б., Хоу Сюели Обработка и интерпретация геофизических данных методами вероятностно-статистического подхода с использованием компьютерной технологии «КОСКАД 3D» // Вестник КРАУНЦ. Науки о Земле. - 2010. - № 2, Вып.16. - С. 126-132.

9. Страхов В.Н. Основные идеи и методы извлечения информации из данных гравитационных и магнитных наблюдений. // Теория и методика интерпретации гравитационных и магнитных аномалий: [сб. ст.] / Ин-т Физики Земли АН СССР. - М.: ИФЗ, 1979. - С. 146-269.

10. Христенко Л.А. Использование вейвлет-преобразования при интерпретации электроразведочных данных (на примере ВКМКС) // Геология и полезные ископаемые Западного Урала: Сб. ст. по материалам юбилейной конф., посвящ. 100-летию Перм. ун-та и 85 -летию геологич. ф-та / ПГНИУ; под общ. ред. Р.Г. Ибламинова. - Пермь, 2016. - С. 143-146.

11. Христенко Л.А., Степанов Ю.И. Электрометрические наблюдения при оценке влияния выработанного пространства недр на основание железнодорожной насыпи // Естественные и технические науки. 2014. - № 7. - C. 58-62.

12. Христенко Л.А., Степанов Ю.И., Кичигин А.В., Паршаков Е.И., Тайницкий А.А., Ширяев К.Н. Совершенствование интерпретации данных мониторинговых электроразведочных наблюдений с помощью аппарата теории оценок // Инженерная геофизика 2017: материалы 13-й науч.-практ. конф. и выставки. - Кисловодск, 2017. - DOI 10.3997/2214-4609.201700419. Электрон. изд. режим доступа:

13. Hristenko L., Stepanov Yu., Kichigin A., Parshakov E., Tainitsky A. Interpretation of electroprospecting monitoring observations with use of probabilistic-statistical characteristics // Engineering and mining Geophysics 2018: 14th Conference \& Exhibition, 23-27 april 2018. - Almaty, 2018. - code 137600. DOI: 10.3997/2214-4609.201800511.

14. Khristenko L.A., Stepanov Ju.I., Kichigin A.V., Parshakov E.I., Tainickiy A.A., Shiryaev K.N. Using of Probabilistic-Statistical Characteristics in the Interpretation of Electrical Survey Monitoring Observations // Practical and Theoretical Aspects of Geological Interpretation of Gravitational, Magnetic and Electric Fields: Proceedings of the 45th Uspensky International Geophysical Seminar, Kazan, Russia / ed. D. Nurgaliev, N. Khairullina; Kazan Federal University. - Springer, Cham, 2019. - P. 313-320. - (Book series: Springer Proceedings in Earth and Environmental Sciences). DOI: 10.3997/2214-4609. 201700419.

\title{
РАЗВИТИЕ МАЛОГЛУБИННЫХ СКВАЖИННЫХ СЕЙСМОРАЗВЕДОЧНЫХ ИССЛЕДОВАНИЙ ДЛЯ ОБЕСПЕЧЕНИЯ БЕЗОПАСНОСТИ ВЕДЕНИЯ ГОРНЫХ РАБОТ
}

\author{
А.В. Чугаев \\ Горный институт УрО РАН, г. Пермь
}

\begin{abstract}
Аннотация: Приведен обзор скважинных сейсморазведочных методик, применяемых на Верхнекамском месторождении калийных солей для обеспечения безопасности ведения горных работ. Рассмотрены особенности методических решений. Отмечены перспективные направления исследований, которые могут повысить информативность скважинных сейсморазведочных работ.

Ключевые слова: межскважинное просвечивание, вертикальное сейсмопрофилирование, сейсмоакустический каротаж, скважинное профилирование ОГТ.
\end{abstract}

Скважинные сейсморазведочные исследования имеют ряд особенностей по сравнению с наземными. Основным преимуществом скважинных исследований является непосредственная близость к объекту изучения, что избавляет волновое поле от фильтрующего воздействия рыхлых приповерхностных отложений, вследствие чего спектр регистрируемого сигнала существенно выше при сравнимых удалениях источника и приемника, и записи в большинстве случаев имеют более высокое отношение сигнал/шум. В свою очередь, проведение скважинных исследований требует бурения и специального обустройства скважин для выполнения геофизических работ, что существенно увеличивает стоимость и время выполнения таких ис- 
следований. При этом волновое поле, регистрируемое при скважинных сейсморазведочных исследованиях, содержит информацию о среде, окружающей скважину, извлечение которой может оправдать затраты на подготовку и проведение скважинной сейсморазведки.

Основной задачей скважинных сейсморазведочных исследований является определение структурно-физических характеристик околоскважинного массива надсолевого интервала: скорости распространения упругих волн, положения акустических и литологических границ. На основании их изучения локализуются природно-техногенные неоднородности.

Скважинные исследования можно разбить на три основные группы по пространственной организации систем регистрации.

Первая группа включает методы «скважина - поверхность», когда источники расположены в скважине, а приемники на поверхности, или наоборот. Сюда относятся все виды ВСП: продольное, непродольное, площадное в прямом или обращенном варианте.

Продольное ВСП позволяет получать скоростной разрез вдоль ствола скважины. Как правило, данная модификация выполняется в 3С модификации для получения $\mathrm{P}$ и $\mathrm{S}$ скоростей с последующим переходом к физико-механическим свойствам околоскважинного массива (ПМ ВСП).

При непродольном ВСП регистрируется серия сейсмограмм от источников, расположенных по профильной линии, проходящей через устье скважины, что позволяет получать многолучевое покрытие плоскости секущей скважину и профиль возбуждения колебаний.

Площадное ВСП представляет собой пространственный вариант непродольного ВСП и позволяет строить площадные срезы скоростной характеристики разреза вокруг скважины. При этом по сравнению с 2D вариантом плотность данных существенно ниже за счет распределения точек преломления по третьей пространственной координате.

В настоящее время все применяемые методики ВСП базируются на изучении поля первых вступлений, в то время как последующая запись несет информацию об отраженных волнах, возникающих на акустических границах, связанных с изменением литологического состава отложений, преимущественно в горизонтальной плоскости. Технология МОВ ВСП имеет детально проработанную теоретическую базу и широко применяется в нефтяной сейсморазведке [1, 4-7, 10, 13]. Кроме того, в аварийных и потенциально опасных зонах с переменой координат Z и X можно получать отражения от вертикальных трещин с последующим картированием наиболее опасных участков (рис. 1). Для возможности выполнения подобных исследований необходимо провести обоснование систем регистрации и обработки получаемых данных при малоглубинных скважинных исследованиях применительно к геологическим условиям Верхнекамского месторождения.

a)

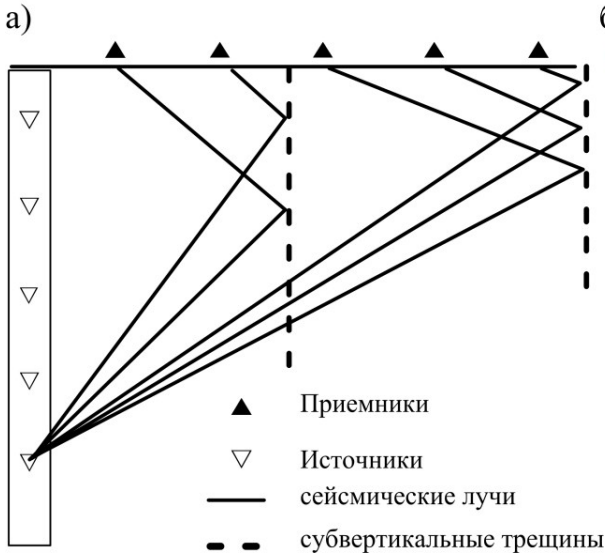

б)

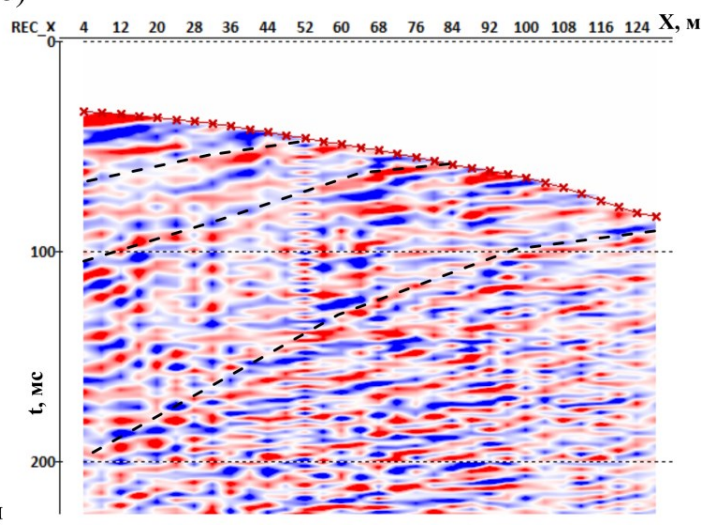

Рис. 1. Отражения от вертикальных трещин: а) схема образования и регистрации отражений сейсмических лучей от субвертикальных трещин б) сейсмограмма с выделенным полем отраженных волн 
Вторая группа методов включает межскважинные исследования. Базовой методикой на Верхнекамском месторождении в настоящее время является межскважинное просвечивание на продольных проходящих волнах. Основные получаемые результаты скоростная характеристика продольных волн межскважинного пространства. Особенности методики межскважинной томографии на Верхнекамском месторождении подробно описаны в работе [9]. К выводам в работе необходимо добавить обязательное комплексирование межскважинных наблюдений и ВСП, объединяемых в единый лучевой массив, и являющийся реализацией трехсторонней расстановки многолучевой томографии (рис. 2). Такой подход позволяет существенно повысить горизонтальную разрешающую способность томографии.

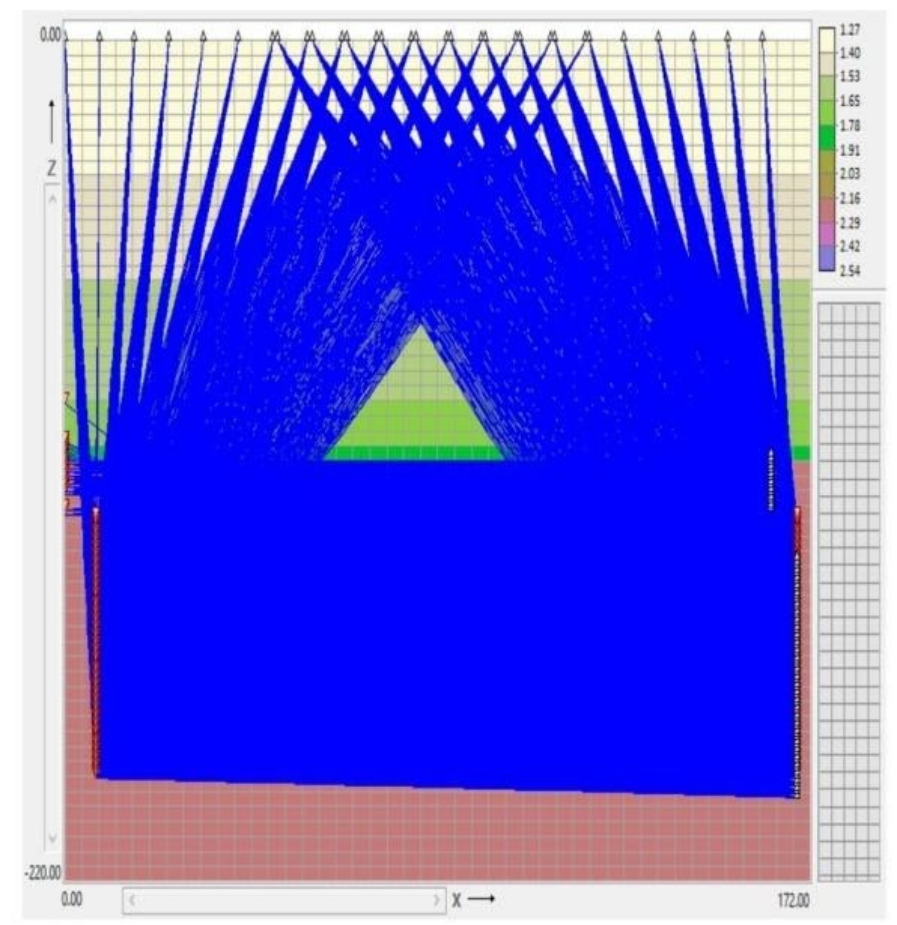

Рис. 2. Схема лучевого покрытия при трехсторонней расстановке источников и приемников при межскважинном просвечивании

Метод межскважинной томографии на проходящих волнах, так же как и при ВСП, основывается на изучении поля первых вступлений, с присущими данному подходу ограничениями и недостатками. В частности, лучевая модель распространения упругих волн в большинстве случаев не учитывает их объемный характер, а траектория лучей очень сильно зависит от начальной скоростной модели среды. Кроме того, при выделении поля первых вступлений большую роль играет субъективное восприятие обработчика-интерпретатора, связанное с выбором фазы слежения.

Возможно расширение применимости межскважинных исследований за счет изучения поля головных волн, возникающих на жесткой акустической границе при переходе от терригенных отложений к соляным. В частности, в работе [8] обосновано изучение скоростного разреза вдоль стволов приемной и излучающей скважин с помощью анализа годографов головных волн, регистрируемых при межскважинных исследованиях. Получаемый разрез является одномерной характеристикой скорости в непосредственной близости от скважины. Кроме того, головная волна при прохождении снизу вверх генерирует поле отраженных волн, которые несут информацию об акустических свойствах среды вблизи скважины. Глубинный сейсмический разрез, полученный таким образом, является двухмерным и строится в области существования регистрируемой го- 
ловной волны. Верхняя частота спектра головной волны намного больше, чем при ВСП, что позволяет получать разрез скорости с разрешением до 1 м по вертикали и 0,6 м по горизонтали.

Еще одним перспективным направлением межскважинных исследований является изучение поля отраженных волн, возникающих на акустических границах, присутствующих в разрезе. В нефтяной и инженерной сейсморазведке есть ряд работ в данной области $[1,11,12]$, однако существует несколько нерешенных проблем технического характера, связанных с привязкой положения точек отражения и корректным суммированием сейсмических трасс для получения сейсмического разреза. Кроме того, необходимо принимать во внимание, что при крутых углах падения площадка отражения, определяемая шириной первой зоны Френеля, будет больше, чем для вертикального луча (рис. 3) и равна $\mathrm{d}=\sqrt{\mathrm{L} \lambda} / \sin \alpha$ ( $\mathrm{L}-$ путь луча, $\lambda$ - длина волны), соответственно, часть лучей, близких к горизонтальным, необходимо исключать, поскольку они будут отражаться от участка сейсмической границы значительной протяженности.

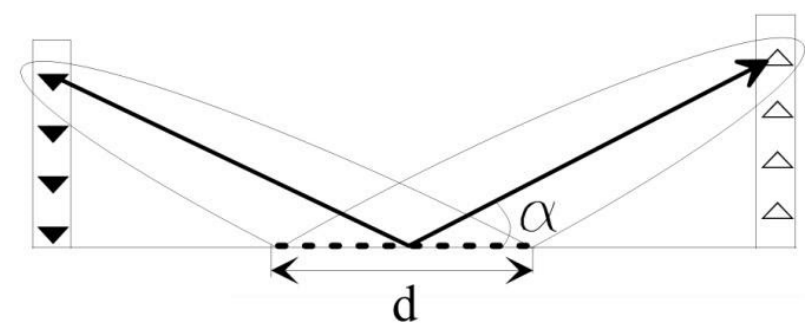

Рис. 3. Схема определения ширины площадки отражения при больших углах падения

Третьим направлением являются сейсморазведочные исследования, при которых источник и приемники находятся в одной скважине. В первую очередь к таким исследованиям относится скважинный каротаж на продольных, Лэмба-Стоунли и, при определенных условиях, на поперечных волнах. Результатом таких исследований являются одномерные разрезы скоростей продольных и гидроволн, а так же трассы отраженных волн обоих типов.

В настоящее время внедряется инновационная методика профилирования ОГТ в скважинах. В отличие от наземного профилирования ОГТ с однозначной ориентацией направленности источников возбуждения колебаний при скважинном профилировании имеется проблема идентификации направления прихода отраженных волн, которая может быть решена с помощью привлечения дополнительной информации об особенностях строения и акустических характеристиках вмещающих пород. Так, профилирование ОГТ успешно применяется для определения толщины ледопородного ограждения при строительстве шахтных стволов [3].

\section{Выводы}

Скважинные исследования на Верхнекамском месторождении решают ряд задач по определению скоростной характеристики непосредственно около скважины, в ближней зоне и в межскважинном пространстве, преимущественно для продольных волн. Каротажные исследования позволяют также изучать скорости поперечной волны и переходить к физико-механическим оценкам. Кроме того, сделаны шаги к получению структурных построений межскважинного пространства.

Основные перспективы развития скважинных исследований по большей части связанны именно с изучением волнового поля, следующего за первыми вступлениями. В первую очередь это изучение поля отраженных волн, зарегистрированных при верти- 
кальном сейсмопрофилировании и при межскважинных исследованиях, которое позволит выполнять структурные построения с высокой степенью детальности. Кроме того, на аварийных и потенциально опасных участках изучение поля отраженных волн позволит выделять зоны вертикальной и субвертикальной трещиноватости.

Исследование выполнено при финансовой поддержке Программь ФНИ, проект № 0422-2019-0146-С-02 (регистрачионный номер темы НИОКТР: ААAА-А18118040690028-5)

\section{БИБЛИОГРАФИЧЕСКИЙ СПИСОК}

1. Гайнанов В.Г., Скворцов А.Г. Комплексное использование технологий скважинных сейсмических наблюдений при инженерно-геологических исследованиях // Разведка и охрана недр. - 2006. - № 12. - С. 30-32.

2. Гальперин Е.И. Вертикальное сейсмическое профилирование. - 2-е изд., доп. и перераб. - М.: Недра, 1982. -344 с.: ил.

3. Способ контроля толщины ледопородного ограждения при строительстве шахтных стволов: пат. 2706910 Рос. Федерация: МПК G 01 V 1/00 (2019.08)... / Санфиров И.А., Ярославцев А.Г., Бабкин А.И., Чугаев А.В.; патентообладатель: ПФИЦ УрО РАН. - № 2019109327. заявл. 29.03.2019; опубл. 21.11.2019. - Бюл. № 33 .

4. Силаев В. А. Скважинная сейсморазведка по методу глубинного сейсмического торпедирования [Электронное издание]. - Пермь: ПГНИИУ, 2018. - 220 c. - URL: https://elis.psu.ru/node/496989 (Дата обращения: 20.05.2020).

5. Табаков А.А., Баранов К.В., Рыковская Н.В., Копчиков А.В. Методика и некоторые результаты обработки данных МОГ и 3D ВСП // Технологии сейсморазведки. - 2006. - № 2. - С. 8-13.

6. Теплицкий В.А. Применение скважинной сейсморазведки для изучения структур в нефтегазоносных районах. - М.: Недра, 1973. - 131 с.: ил. - (Тр. ВНИГНИ. Вып. 132).

7. Шехтман Г.А. Формирование изображений среды в методе ВСП // Технологии сейсморазведки. 2016. - № 3. - C. 5-21. DOI: 10.18303/1813-4254-2016-3-5-21.

8. Chugaev A.V., Lisin V.P., Babkin A.I., Tomilov K.J. The analysis of the head waves registered in crosshole survey for calculation velocities in the vicinity of boreholes // 16th Conference and Exhibition Engineering Geophysics - Perm, 2020. -(принято к печати).

9. Chugaev A.V., Lisin V.P., Sanfirov I.A., Nikiforov V.V.. Zelenin V.P. Cross-section velocity characteristics determination by seismic acoustic borehole methods // Engineering Geophysics 2017: $13^{\text {th }}$ Conference and Exhibition on Engineering Geophysics 2017. - Kislovodsk, 2017. - Code 129037. DOI: 10.3997/22144609.201700413

10. Gaiser J. 3C Seismic and VSP: Converted waves and vector wavefield application // SEG Books, 2016. $640 \mathrm{p}$.

11. Li G., Stewart R.R. Common reflection-point stacking of crosswell seismic data: Friendswood, Texas // // SEG Technical Program Expanded Abstracts. - 1994. - P. 42-45. https:doi.org/10.1190/1.1932116.

12. Smalley N., Harris J.M. CDP stacking and imaging of cross-well reflectors // SEG Technical Program Expanded Abstracts. - 1992. - P. 87-90. - https:doi.org/10.1190/1.1822244.

13. O’Brien,J., B.Farmani, B.Atkinson VSP imaging using free-surface multiples: A case study from the Gulf of Mexico // The Leading Edge. - 2013. - V. 32. - P. 1177-1300. - https://doi.org/10.1190/tle32101258.1 